\title{
APLIKASI METODA CRITICAL PATH METHOD (CPM) DALAM PENJADWALAN KEGIATAN PEMBANGUNAN PERUMAHAN
}

\author{
Sutanto \\ Program Studi Diploma III Teknik Sipil \\ Sekolah Vokasi Universitas Diponegoro
}

\begin{abstract}
Sutanto, in this paper explian that the development of housing development in Indonesia is now showing a very rapid progress in line with the rate of population growth and the increase in income per capita community, so that housing demand is getting bigger. For that much needed planning and scheduling activities of a good housing development projects in accordance with the progress of science and technology in order to have added value to the implementation of the housing development. The Critical Path Method (CPM) application research in guarding housing development activities and the impact on technical constraints in the field is one solution. Based on the results of data processing shows that the use of scheduling activities of housing development projects with Critical Path Method method has resulted in more added value.
\end{abstract}

Keywords: housing, scheduling, CPM

\section{PENDAHULUAN}

Perkembangan pembangunan perumahan di Indonesia saat ini menunjukkan kemajuan yang sangat pesat seiring dengan laju pertumbuhan penduduk dan peningkatan penghasilan perkapita masyarakat, sehingga kebutuhan perumahan semakin besar. Untuk itu sangat dibutuhkan perencanaan dan penjadwalan kegiatan proyek pembangunan perumahan yang baik sesuai dengan kemajuan ilmu dan teknologi agar mempunyai nilai tambah terhadap pelaksanaan pembangunan perumahan tersebut.

Penjadwalan proyek merupakan salah satu elemen hasil perencanaan, yang dapat memberikan informasi tentang jadwal rencana dan kemajuan proyek dalam hal kinerja sumber daya berupa biaya, tenaga kerja, peralatan dan material serta rencana durasi proyek dan progres waktu untuk penyelesaian proyek. Dalam proses penjadwalan, penyusunan kegiatan dan hubungan antar kegiatan dibuat lebih terperinci dan sangat detail. Hal ini di maksudkan untuk membantu pelaksanaan evaluasi proyek. Penjadwalan atau schedulling adalah pengalokasian waktu yang tersedia untuk melaksanakan masingmasing pekerjaan dalam rangka menyelesaikan suatu proyek hingga tercapai hasil optimal dengan mempertimbangkan keterbatasan-keterbatan yang ada (Husen : 2009). Tujuan yang akan dicapai dalampenelitian adalah menganalisa metoda Line of Balance dan metoda Critical Path Method untuk proyek pembangunan perumahan.

\section{TINJAUAN PUSTAKA}

Bar Chart ditemukan oleh Gantt dan Fredict W. Taylor tahun 1917, dalam bentuk bagan balok, dengan panjang balok sebagai representasi dari durasi setiap kegiatan. Format bagan balok informatif, mudah dibaca dan efektif untuk komunikasi serta dapat dibuat dengan mudah dan sederhana. Bagan balok terdiri atas sumbu y yang menyatakan kegiatan atau paket kerja dari lingkup proyek, sedangkan sumbu $\mathrm{x}$ menyatakan satuan waktu dalam hari, minggu, atau bulan sebagai durasi nya. Pada bagan ini juga dapat ditentukan milestone sebagai bagian target yang harus diperhatikan guna kelancaran produktivitas proyek secara keseluruhan. Untuk proses updating bagan balok dapat di perpendek atau di perpanjang yang menunjukkan bahwa durasi kegiatan akan bertambah atau berkurang sesuai kebutuhan dalam proses perbaikan jadwal $^{[1]}$.

Line-of-Balance (LOB) adalah variasi dari metoda penjadwalan linier yang memungkinkan keseimbangan operasi sehingga setiap kegiatan dapat terus berlangsung. Manfaat utama dari metodologi $L O B$ adalah bahwa metoda ini menyediakan informasi tentang tingkat produksi dan durasi dalam bentuk format grafis sehingga mudah ditafsirkan. Plot $L O B$ dapat menunjukkan sekilas apa yang salah dengan kemajuan suatu kegiatan, dan dapat mendeteksi kemacetan potensial di masa depan. Jelas, $L O B$ memungkinkan pemahaman yang lebih baik dari proyek dengan aktivitas yang berulang daripada teknik penjadwalan lain, karena memungkinkan untuk menyesuaikan tingkat kegiatan produksi. Hal ini memungkinkan efisiensi dan kelancaran dalam pengelolaan sumber daya, dan membutuhkan usaha dan waktu yang lebih singkat untuk menghasilkan jadwal network ${ }^{[2,3]}$.

Network diagram ini biasa di gunakan untuk mengendalikan sejumlah kegiatan yang memiliki ketergantungan yang kompleks. Sehingga metode ini mempunyai kelebihan dengan memperhitungkan dan mengetahui waktu terjadinya setiap kejadian yang ditimbulkan oleh satu atau beberapa kegiatan, kesukaran - kesukaran yang bakal timbul dapat di ketahui jauh sebelum terjadi sehingga tindakan pencegahan yang diperlukan dapat di lakukan, sehingga memungkinkan tercapainya hasil proyek yang lebih ekonomis. Activity on Arrow atau biasa 
disebut Critical Path Method (CPM) terdiri dari anak panah dan lingkaran/segi-empat. Anak panah menggambarkan kegiatan/aktifitas, sedangkan lingkaran/segi-empat menggambarkan kejadian (Event). Kejadian (event) di awal anak panah disebut "I", sedangkan kejadian (event) di akhir anak panah disebut "J"[4].

\section{METODE PENELITIAN}

Obyek dalam penelitian ini adalah proyek pembangunan perumahan Tugu Sinar Waluyo Semarang oleh PT. Hikmah Sejati. Adapun yang dijadikan sampel untuk mengeksplorasi metoda perencanaan dan penjadwalan proyek pembangunan perumahan dalam penelitian ini adalah pembangunan 10 unit rumah type 36/90. Selanjutnya obyek ke 2 adalah proyek pembangunan perumahan Permata Puri Semarang oleh PT. Pembangunan Perumahan. Adapun yang dijadikan sampel untuk mengeksplorasi metoda perencanaan dan penjadwalan proyek pembangunan perumahan dalam penelitian ini adalah pembangunan 10 unit rumah type 45/90.

Lokasi penelitian merupakan proyek pembangunan perumahan Tugu Sinar Waluyo Semarang di Jl. Sinar Kencana V Semarang, Kantor pemasaran PT. Hikmah Sejati di Jl. Tlogosari Raya II. Sedangkan lokasi penelitian 2 adalah proyek pembangunan perumahan Permata Puri Semarang di J1 Semarang - Boja, Kantor pemasaran PT. Pembangunan Perumahan di Jl. Bukit Barisan Raya - Permata Puri Ngalian Semarang.

\section{Data Primer dan Sekunder}

Pengumpulan data primer adalah data yang diperoleh langsung dari obyek penelitian berupa : informasi, pengamatan, wawancara langsung dengan pihak - pihak yang terkait, data schedule dan laporan - laporan proyek. Dalam penelitian ini data yang dibutuhkan adalah data perencanaan pembangunan 10 (Sepuluh) unit rumah type 36/90 untuk pembangunan perumahan Tugu Sinar Waluyo dan 10 (sepuluh) unit rumah type 45/120 untuk pembangunan perumahan Permata Puri. Dan data sekunder diperoleh dengan melakukan studi pustaka untuk melengkapi data primer dan untuk memperdalam materi penelitian.

\section{Observasi / Survey Lapangan}

Peneliti melakukan observasi pada pekerjaan yang dijadikan sampel penelitian untuk mendapatkan data - data perkembangan proyek yang dibutuhkan, kendala teknis yang terjadi di lapangan.

\section{Analisis Data}

Setelah data terkumpul akan dilakukan analisis data dan elaborasi dari data aplikasi penjadwalan kegiatan metode Critical Path Method (CPM) serta analisis dampak pengaruh dari kendala teknis di lapangan terhadap aplikasi penjadwalan. Pembahasan hasil analisis aplikasi penjadwalan metoda Critical Path Method serta pengaruh terhadap kendala teknis di lapangan, untuk bisa mendapatkan ilmu pengetahuan tentang metoda penjadwalan kegiatan proyek pembangunan perumahan yang lebih baik dan bermanfaat.

\section{HASIL DAN PEMBAHASAN}

Penjadwalan metoda Critical Path Method adalah hasil aplikasi dari metoda Bar Chart untuk pembangunan perumahan Tugu Sinar Waluyo yang disajikan di tabel 1. Kegiatan ada pada anak panah disertai jumlah durasi masing - masing kegiatan. Hasil perhitungan arah maju (forword pass) untuk mendapatkan nilai ES (earliest start) dan EF (earliest finish) serta arah mundur (back pass) untuk mendapatkan nilai LF (latest finish) dan LS (latest start). Pada node yang menunjukkan nomor event $\mathrm{I}$, EETi menunjukkan nilai ES, sedangkan pada nomor event $\mathrm{J}$, LETj menunjukkan nilai LF, Nilai EF = ES + durasi kegiatan dan nilai LS $=$ LF - durasi kegiatan. Kelebihan dari metoda CPM dapat menunjukkan lintasan kritis. Lintasan kritis adalah lintasan dengan kumpulan kegiatan yang mempunyai durasi terpanjang yang dapat diketahui bila kegiatannya mempunyai Total Float $(\mathrm{TF})=0$. Dari gambar 5.10. dapat dilihat lintasan kritis : A1 - B1 - D1 - D2 - F - K - L, dengan Durasi 112 hari. Kelemahan dari metoda tesebut tidak dapat memperhitungkan produktifitas pada proyek yang mempunyai kegiatan berulang. 
Tabel 1. Analisa diagram metoda Critical Path Method (CPM) pembangunan Perumahan Tugu Sinar Waluyo

\begin{tabular}{|c|c|c|c|c|c|c|c|c|}
\hline Kegiatan & $\begin{array}{c}\text { Uraian } \\
\text { Pekerjaan }\end{array}$ & $\begin{array}{c}\text { Durasi } \\
\text { (Hari) }\end{array}$ & $\mathbf{E S}$ & $\mathbf{E F}$ & $\mathbf{L F}$ & $\mathbf{L S}$ & $\mathbf{T F}$ & FF \\
\hline A1 & Pekerjaan persiapan & 7 & 0 & 7 & 7 & 0 & 0 & 0 \\
\hline $\mathrm{A} 2$ & Pekerjaan persiapan & 21 & 7 & 112 & 112 & 7 & 0 & 84 \\
\hline B1 & Pekerjaan tanah \& pondasi & 7 & 7 & 14 & 14 & 7 & 0 & 0 \\
\hline B2 & Pekerjaan tanah \& pondasi & 21 & 14 & 112 & 112 & 14 & 0 & 77 \\
\hline $\mathrm{C} 1$ & Pekerjaan pasangan \& kusen & 7 & 21 & 28 & 59 & 21 & 31 & 0 \\
\hline $\mathrm{C} 2$ & Pekerjaan pasangan \& kusen & 7 & 28 & 35 & 74 & 59 & 39 & 0 \\
\hline $\mathrm{C} 3$ & Pekerjaan pasangan \& kusen & 38 & 35 & 112 & 112 & 74 & 0 & 39 \\
\hline D1 & Pekerjaan beton bertulang & 7 & 14 & 21 & 21 & 14 & 0 & 0 \\
\hline D2 & Pekerjaan beton bertulang & 14 & 21 & 35 & 35 & 21 & 0 & 0 \\
\hline D3 & Pekerjaan beton bertulang & 35 & 35 & 112 & 112 & 35 & 0 & 42 \\
\hline E1 & Pekerjaan plesteran \& lantai & 7 & 28 & 35 & 66 & 59 & 31 & 0 \\
\hline E2 & Pekerjaan plesteran \& lantai & 35 & 35 & 112 & 112 & 66 & 0 & 42 \\
\hline $\mathrm{F}$ & Pekerjaan rangka atap \& penutup & 42 & 35 & 77 & 77 & 35 & 0 & 0 \\
\hline G1 & Pekerjaan pintu \& plafond & 7 & 35 & 42 & 73 & 66 & 31 & 0 \\
\hline $\mathrm{G} 2$ & Pekerjaan pintu \& plafond & 39 & 42 & 112 & 112 & 73 & 0 & 31 \\
\hline $\mathrm{H}$ & Pekerjaan instalasi listrik & 21 & 42 & 112 & 112 & 73 & 0 & 49 \\
\hline I1 & Pekerjaan sanitasi & 7 & 35 & 42 & 98 & 74 & 56 & 0 \\
\hline $\mathrm{I} 2$ & Pekerjaan sanitasi & 14 & 42 & 112 & 112 & 98 & 0 & 56 \\
\hline $\mathrm{J}$ & Pekerjaan plumbing & 21 & 42 & 112 & 112 & 98 & 0 & 49 \\
\hline $\mathrm{K}$ & Pekerjaan teras & 14 & 77 & 91 & 91 & 77 & 0 & 0 \\
\hline $\mathrm{L}$ & Pekerjaan finishing & 21 & 91 & 112 & 112 & 91 & 0 & 0 \\
\hline
\end{tabular}

Keterangan:

- $\quad$ Lintasan kritis : A1 - B1 - D1 - D2 - F - K - L

- Durasi terpanjang : 112 hari

Tabel 2. Analisa diagram metoda Critical Path Method (CPM) pembangunan Perumahan Permata Puri

\begin{tabular}{clccccccc}
\hline Kegiatan & \multicolumn{1}{c}{$\begin{array}{c}\text { Uraian } \\
\text { Pekerjaan }\end{array}$} & $\begin{array}{c}\text { Durasi } \\
\text { (Hari) }\end{array}$ & ES & EF & LF & LS & TF & FF \\
\hline A1 & Pekerjaan persiapan & 7 & 0 & 7 & 7 & 0 & 0 & 0 \\
A2 & Pekerjaan persiapan & 21 & 7 & 112 & 112 & 7 & 0 & 84 \\
B1 & Pekerjaan tanah & 7 & 7 & 14 & 14 & 7 & 0 & 0 \\
B2 & Pekerjaan tanah & 21 & 14 & 112 & 112 & 14 & 0 & 77 \\
C1 & Pekerjaan pondasi & 7 & 14 & 21 & 21 & 14 & 0 & 0 \\
C2 & Pekerjaan pondasi & 28 & 21 & 112 & 112 & 21 & 0 & 63 \\
D1 & Pekerjaan beton bertulang & 7 & 21 & 28 & 28 & 21 & 0 & 0 \\
D2 & Pekerjaan beton bertulang & 28 & 28 & 56 & 56 & 28 & 0 & 0 \\
D3 & Pekerjaan beton bertulang & 21 & 56 & 112 & 112 & 56 & 0 & 35 \\
E1 & Pekerjaan pasangan \& kusen & 10 & 28 & 38 & 66 & 28 & 28 & 0 \\
E2 & Pekerjaan pasangan \& kusen & 15 & 38 & 53 & 85 & 66 & 32 & 0 \\
E3 & Pekerjaan pasangan \& kusen & 27 & 53 & 112 & 112 & 85 & 0 & 32 \\
F1 & Pekerjaan plesteran \& lantai & 7 & 38 & 45 & 73 & 66 & 28 & 0 \\
F2 & Pekerjaan plesteran \& lantai & 28 & 45 & 112 & 112 & 73 & 0 & 39 \\
G & Pekerjaan rangka atap \& penutup & 35 & 56 & 91 & 91 & 56 & 0 & 0 \\
H1 & Pekerjaan pintu \& plafond & 7 & 45 & 52 & 80 & 73 & 28 & 0 \\
H2 & Pekerjaan pintu \& plafond & 32 & 52 & 112 & 112 & 80 & 0 & 28 \\
I & Pekerjaan instalasi listrik & 28 & 52 & 112 & 112 & 80 & 0 & 32 \\
J1 & Pekerjaan sanitasi & 7 & 53 & 60 & 98 & 85 & 38 & 0 \\
J2 & Pekerjaan sanitasi & 14 & 60 & 112 & 112 & 98 & 0 & 38 \\
K & Pekerjaan plumbing & 21 & 60 & 112 & 112 & 98 & 0 & 31 \\
L & Pekerjaan finishing & 21 & 91 & 112 & 112 & 91 & 0 & 0 \\
\hline
\end{tabular}


Selanjutnya penjadwalan metoda Critical Path Method (CPM) merupakan hasil aplikasi dari metoda Bar Chart untuk pembangunan perumahan Permata Puri yang disajikan di tabel 2, di mana kegiatannya disertai jumlah durasi masing - masing kegiatan. Hasil perhitungan arah maju (forword pass) untuk mendapatkan nilai ES (earliest start) dan EF (earliest finish) serta arah mundur (back pass) untuk mendapatkan nilai LF (latest finish) dan LS (latest start). Pada node yang menunjukkan nomor event I, EETi menunjukkan nilai ES, sedangkan pada nomor event $\mathrm{J}$, LETj menunjukkan nilai $\mathrm{LF}$, Nilai $\mathrm{EF}=\mathrm{ES}+$ durasi kegiatan dan nilai $\mathrm{LS}=\mathrm{LF}-$ durasi kegiatan

\section{KESIMPULAN}

Hasil kajian studi literatur dan pembahasan analisa aplikasi penjadwalan Critical Path Method serta dampak kendala teknis di lapangan pada pembangunan perumahan Tugu Sinar Waluyo dan Permata Puri, dapat ditarik kesimpulan sebagai berikut:

Aplikasi penjadwalan metoda Critical Path Method pada proyek pembangunan perumahan secara analisis cukup baik, dapat mengetahui aktivitas pekerjaan yang mengalami hambatan ataupun keterlambatan pada setiap kegiatan pekerjaan. Metoda ini juga mampu memonitor kemajuan beberapa kegiatan tertentu yang berada dalam suatu penjadwalan keseluruhan proyek. Pengaruh terhadap kendala teknis di lapangan masih dapat diatasi dengan baik sehingga tidak mengganggu produksi kegiatan maupun lama waktu penyelesaian proyek. Maka dari itu metoda metoda Critical Path Method (CPM) cukup efektif digunakan pada penjadwalan pembangunan perumahan dengan catatan, kendala - kendala teknis antara lain : unsur tenaga kerja, peralatan dan pengadaan bahan material harus dipersiapkan dengan baik.

Aplikasi penjadwalan metoda Critical Path Method diujicobakan pada pembangunan perumahan sebenarnya mempunyai keandalan dalam menunjukkan secara spesifik hubungan logika ketergantungan antar kegiatan dan dapat menentukan lintasan kritis kegiatan pekerjaan sehingga kegiatan yang menjadi prioritas apabila terjadi keterlambatan dapat diketahui. Karena metoda Critical Path Method tidak dapat mewakili atau menyeimbangkan tingkat produksi yang mempunyai aktifitas berulang, maka ketidak seimbangan produksi dapat secara negatif berdampak pada kinerja proyek yang dapat menyebabkan terhentinya kegiatan pekerjaan, inefisiensi penggunaan alokasi sumber daya dan peningkatan biaya proyek. Pengaruh kendala teknis di lapangan masih dapat diatasi dengan baik sehingga tidak mengganggu produksi kegiatan adapun lama waktu pelaksanaan proyek bertambah 1 hari, semula 112 hari menjadi 113 hari. Penggunaan metoda Critical Path Method pada proyek pembangunan perumahan alangkah baiknya dikombinasikan dengan metoda Line of Balance.

Demi kepentingan pengembangan ilmu tentang metoda penjadwalan, maka perlu penelitian lebih lanjut untuk bisa mendapatkan metoda penjadwalan proyek pembangunan perumahan yang lebih tepat. Untuk para pelaku pengembang perumahan, dalam perencanaan penjadwalan proyek disarankan memakai metoda Critical Path Method $(C P M)$, karena kelebihan dari metoda yang satu akan menutup kekurangan yang lain dengan catatan : tenaga kerja, peralatan dan pengadaan bahan material harus dipersiapkan dengan baik.

\section{DAFTAR PUSTAKA}

1. Husen, 2009, Manajemen Proyek Perencanaan, Penjadwalan \& Pengendalian Proyek., Penerbit Andi, Yogyakarta.

2. Arditi, dan Albulak, 1986, Line of Balance Schedulling in Pavement Construction, J. Constr. Eng. and Mgmt., ASCE, 112(3), 411424.

3. Arditi, Tokdemir, O.B. dan Suh K., 2002 , Challenges in Line of Balance Schedulling, J. Constr. Eng, and Mgmt., ASCE, 112(3), 411424.

4. Ervianto, Wulfram, I. 2005, Manajemen Proyek Konstruksi (Edisi Revisi), Edisi III, Andi, Yogyakarta. 